\title{
BMJ Open Association between earthquake experience and depression 37 years after the Tangshan earthquake: a cross- sectional study
}

\author{
Xing Gao, ${ }^{1}$ Yue Leng, ${ }^{2}$ Yuchen Guo, ${ }^{1}$ Jichun Yang, ${ }^{3}$ Qinghua Cui, ${ }^{3}$ Bin Geng, ${ }^{4}$ \\ Hongpu Hu, ${ }^{1}$ Yong Zhou ${ }^{5}$
}

To cite: Gao X, Leng Y, Guo Y, et al. Association between earthquake experience and depression 37 years after the Tangshan earthquake: a crosssectional study. BMJ Open 2019;9:e026110. doi:10.1136/ bmjopen-2018-026110

- Prepublication history for this paper is available online. To view these files, please visit the journal online (http://dx.doi org/10.1136/bmjopen-2018026110).

$X G$ and $Y L$ are joint first authors.

Received 23 August 2018

Revised 23 May 2019

Accepted 12 July 2019

Check for updates

(C) Author(s) (or their employer(s)) 2019. Re-use permitted under CC BY-NC. No commercial re-use. See rights and permissions. Published by BMJ.

For numbered affiliations see end of article.

Correspondence to

Dr Yong Zhou;

yongzhou78214@163.com

Dr Hongpu Hu;

hu.hongpu@imicams.ac.cn

\section{ABSTRACT}

Objective To investigate the association between the Tangshan earthquake and depression after 37 years. Design and setting A cross-sectional study conducted in Tangshan from 2013 to 2014 .

Participants The sample included 5024 participants born before 28 July 1976 the date of the Tangshan earthquake, with available data on their earthquake experiences and depression 37 years post-earthquake.

Outcomes and variables The outcome was depression measured using the Center for Epidemiological Study and Depression Scale. The independent variable was earthquake experience, which was classified into three groups: no earthquake experience, earthquake experience without bereavement and earthquake experience with bereavement. Multivariable logistic regression analysis was used to evaluate the association between earthquake experience and depression after adjusting for gender, age at the time of the earthquake, smoking status, drinking status, education, income, residence in Tangshan 1 to 2 years postearthquake, hypertension, diabetes and dyslipidaemia. Results Of the 5024 participants, 641 experienced the Tangshan earthquake, and 98 experienced bereavement due to the earthquake. 37 years after the earthquake, survivors who had lost relatives during the earthquake were nearly three times ( $0 \mathrm{R} 2.82,95 \% \mathrm{Cl} 1.24$ to 6.39 ) as likely to have depression as those who had not experienced the earthquake, while those who had not lost relatives were 1.69 times as likely $(0 \mathrm{R} 1.69,95 \% \mathrm{Cl} 0.93$ to 3.08). Stratified analyses showed that earthquake was significantly associated with depression in women with (OR $3.51,95 \% \mathrm{Cl} 1.21$ to 10.16 ) or without bereavement (OR $3.07,95 \% \mathrm{Cl} 1.44$ to 6.56 ) but not in men; this association was also significant in individuals over 18 years old at the time of the earthquake with $(\mathrm{OR} 13.16,95 \% \mathrm{Cl} 3.08$ to 56.3 ) or without bereavement ( $0 \mathrm{R} 3.39,95 \% \mathrm{Cl} 1.31$ to 8.87 ) but not in individuals less than 18 years old.

Conclusions 37 years after the Tangshan earthquake, earthquake experience was associated with depression among bereaved survivors, women and individuals over 18 years old at the time of the earthquake.

\section{INTRODUCTION}

Depression is predicted to be a major reason for disability around the world by 2030 ,
Strengths and limitations of this study

The study investigated the long-term risk of depression 37 years after a major earthquake.

- Participants were stratified by gender and age at the time of the earthquake.

- We were unable to control for every event or factor, such as adverse childhood experiences, other bereavement or current psychological stressors.

- Only participants who were still alive 37 years after the earthquake were able to participate in the study.

according to the WHO. ${ }^{1}$ In addition, the chronic and debilitating nature of depression complicates the prognosis of chronic diseases, aggravates various diseases and may lead to suicide. ${ }^{2-4}$ Evidence shows that depression is related to demographic characteristics, living habits, education, income and health status. ${ }^{5-7}$ Participants exposed to disasters at an early life stage are at an increased risk of depression in the short term ( 1 to 4 years), independent of age, gender, income, education and other confounders. ${ }^{8-10}$ Additionally, studies report that some survivors have psychological problems in the immediate aftermath of disaster trauma; most of these reactions abate over time, and only a minority of survivors develop a long-standing disorder. ${ }^{11}{ }^{12}$ Therefore, long-term evidence is essential to evaluate the effects of disaster on depression.

Findings regarding the long-term impact of disasters on mental health have been mixed. Several studies have reported no significant differences, ${ }^{13} 14$ but others have revealed more psychological problems in exposed individuals than in non-exposed individuals for more than a decade after disasters. ${ }^{10} 1516$ Moreover, evidence shows that such effects are increased if survivors suffer from bereavement. $^{10}{ }^{12}$ Additionally, the association 
between earthquakes and depression may vary according to age or gender. Studies indicate that overall levels of psychological symptoms may vary among children, adolescents and adults due to differences in physiology and cognition. ${ }^{17} 18$ In response to disaster, women appear to develop more intense and longer-lasting psychological symptoms than men. ${ }^{13}{ }^{19}$ However, very few of these studies investigated the long-term effect of earthquakes on depression risk in the Chinese population.

Our study provides a suitable setting for investigating the long-term impact of earthquakes on depression in the Chinese population. The Tangshan earthquake, which occurred in 1976, had a magnitude of 7.8 on the Richter scale. ${ }^{20}$ The earthquake caused 242769 deaths and left 164851 people severely injured, representing the strongest and deadliest natural disaster in the twentieth century. ${ }^{20}$ Since the earthquake, numerous studies have examined the effects of the event on physical health outcomes. These studies report increased risks of diabetes, cardiovascular disease and elevated levels of uric acid among survivors of the Tangshan earthquake even at time points more than 30 years later. ${ }^{21-23}$ However, no study to date has examined the long-term effect of the Tangshan earthquake on the risk of depression.

The aim of our study was to examine the long-term effect of disaster on depression 37 years later. We hypothesised that the earthquake-exposed group would be more likely than the non-exposed group to exhibit depression. Furthermore, we expected that bereaved survivors would be more likely to experience depression than non-bereaved survivors. Considering that age and gender may confound the association between earthquake experience and depression, we also performed an analysis stratified by age and gender.

\section{METHODS}

\section{Study participants}

The participants were selected from the Jidong cohort, an ongoing community-based prospective study in Chinese adults $^{24}$. The Jidong community is located in the Caofeidian district of Tangshan City, which is approximately $60 \mathrm{~km}$ from the epicentre of the Tangshan earthquake. Cluster sampling was used to select participants. From July 2013 to August 2014, a total of 9078 residents in the Jidong community were recruited to participate in the cohort. Data regarding demographic and behavioural characteristics, insomnia, cognition, depression and biochemical indicators have been collected from this cohort at annual follow-ups since $2013{ }^{25-27}$ These data were collected using a set of self-administered questionnaires (including the Center for Epidemiological Study and Depression Scale (CES-D)) with the assistance of welltrained research nurses during face-to-face interviews. Biomedical variables were collected by physical examinations and laboratory assessments. Research on this cohort originally examined sub-health and later expanded to examine depression, cardiovascular health, cerebrovascular health and other areas. ${ }^{25-28}$

In the current study, we excluded 4054 of the 9078 candidate participants according to the following standards: (1) birth date after 28 July $1976(\mathrm{n}=4053)$, (2) incomplete information on relevant earthquake experience $(n=1)$ and (3) missing values in the surveys for the CES-D measurement scale $(\mathrm{n}=0)$. Missing data for confounding variables (60 income variables) were imputed with their mean values among these participants. Ultimately, a total of 5024 individuals were included in this cross-sectional study. The participants in the Jidong Cohort are subjected to a physical examination annually, which is paid for by the community. Therefore, the response rate was almost $100 \%(5024 / 5025)$.

This study was performed according to guidelines from the Declaration of Helsinki. All participants provided written informed consent.

\section{Assessment of earthquake experience}

The exposure variable of interest was experience with the earthquake. Earthquake experience and related bereavement were collected through a structured questionnaire. These factors were obtained using the following questions: "Were you in the Tangshan earthquake area in 1976?" and "Did you lose any relatives in the earthquake?"23 According to the answers to these questions, subjects were classified into three groups: no earthquake experience, earthquake experience without bereavement and earthquake experience with bereavement.

\section{Assessment of current depression}

Depressive symptoms were assessed using the CES-D, which was initially developed by the US National Institute of Mental Health in 1977. ${ }^{29}$ The Chinese version of the CES-D was translated from the international standard version of the CES-D questionnaire in 1985 by two psychiatrists and was specifically designed to screen for depression. ${ }^{30}$ The CES-D questionnaire surveys the frequency of common depressive symptoms over the past week. Each item in the depression assessment section of the questionnaire is scored from 0 (rarely or none of the time, less than 1 day) to 3 (all of the time, 5 to 7 days). The four positive statement items (item 4 , I felt that I was just as good as other people; item 8, I felt hopeful about the future; item 12, I was happy; item 16, I enjoyed life) are reverse coded to calculate the total score, which ranges from 0 to 60 . A cut-off value of $\geq 16$ has been widely used to define clinically meaningful depressive symptoms. ${ }^{31-33}$ All investigators attended a 3-day training course and were licensed before conducting the CES-D interviews.

\section{Assessment of potential covariates}

The selected covariates included factors known to be predictive of depression and/or potentially correlated with earthquake exposure, including age at the time of the earthquake, gender, education, income, smoking status, drinking status, residence in Tangshan 1 to 2 
years after the earthquake, hypertension, diabetes and dyslipidaemia.

Age at the time of the earthquake was defined as a continuous variable and then a categorical variable (' $\leq 6$ years', ' 6 to 18 years' or ' $\geq 18$ years'). The average monthly income of each family member was categorised as ‘ $<¥ 3000$ ', ' $¥ 3000$ to 5000 ' or ‘ $>¥ 5000$ ’. Educational level was classified into three categories: 'illiteracy or primary school', 'middle school or high school' and 'university or above'. Residence in Tangshan 1 to 2 years after the earthquake was classified as 'yes' and 'no'. Smoking status was classified as 'yes' (current smoker or quit $<12$ months ago) and 'no' (non-smoker or quit $>12$ months ago). Drinking status was divided into 'yes' (current drinking $<$ one standard servings/day, <two standard servings/day, two to four standard servings/day, $\geq$ five standard servings/day) and 'no' (never drank, drank in the past). A standard serving was defined as $15 \mathrm{~g}$ of ethanol. Systolic blood pressure (SBP) and diastolic blood pressure (DBP) were measured twice using a mercury sphygmomanometer with the subject in a seated position. If the difference between the two measurements exceeded $5 \mathrm{~mm}$ $\mathrm{Hg}$, an additional reading was taken, and the average of the three readings was used. Hypertension was defined as having a history of hypertension, exhibiting an SBP $\geq 140 \mathrm{~mm} \mathrm{Hg}$ or a DBP $\geq 90 \mathrm{~mm} \mathrm{Hg}$ or using antihypertensive medications. The definition of diabetes mellitus was a fasting glucose level $\geq 7.0 \mathrm{mmol} / \mathrm{L}(126 \mathrm{mg} / \mathrm{dL})$, current treatment with insulin/oral hypoglycaemic agents or a history of diabetes mellitus. Dyslipidaemia was defined as a history of hyperlipidaemia, a total blood cholesterol level $\geq 220 \mathrm{mg} / \mathrm{dL}$, a triglyceride level $\geq 150 \mathrm{mg} / \mathrm{dL}$ or use of anti-hyperlipidaemic medications. All measures in this cross-sectional study reflected the current values as of data collection.

\section{Statistical analysis}

We first compared the characteristics of individuals according to their earthquake and bereavement experiences (no earthquake experience, earthquake experience without bereavement and earthquake experience with bereavement) using the $\mathrm{X}^{2}$ test for categorical variables and one-way analysis of variance or the Kruskal-Wallis test for continuous variables.

We used logistic regression to examine the association between earthquake experience and current depression, with 'no earthquake experience' as the reference group. Four multivariate models were fitted as follows: Model 1 was the unadjusted model. Model 2 was adjusted for age at the time of the earthquake and gender. Model 3 was further adjusted for smoking status, drinking status, education, income and residence in Tangshan 1 to 2 years after the earthquake. Model 4 was further adjusted for hypertension, diabetes and dyslipidaemia.

We also used multiple logistic regression to examine the association stratified by gender and age at the time of the earthquake. To evaluate whether the effect of the earthquake on depression would be modified by gender and/or age at the time of the earthquake, we tested the statistical significance of earthquake $\times$ genderand earthquake $\times$ age at the time of the earthquake as interaction effects in a multiple-adjustment logistic model by applying a post-estimation Wald test to obtain an omnibus $p$ value for the interactions between earthquake categories and depression.

All statistical tests were two-sided, and results with a $\mathrm{p}$ value $<0.05$ were considered statistically significant. The analyses were performed in SAS V.9.4 (SAS Institute Inc, Cary, North Carolina, USA).

\section{Patient and public involvement}

Patients and the public were not involved in the development of the research question or outcome measures, study design, recruitment or conduct of the study. The results will be disseminated to study participants through annual information events.

\section{RESULTS}

\section{Characteristics of the study participants}

The characteristics of the participants according to earthquake and bereavement experiences are shown in table 1. In total, 5024 participants were included in this study; the participants were $50.2 \%$ male and ranged in age from 37 to 82 years at the time of data collection. Among all participants, 543 (10.8\%) individuals experienced the earthquake without bereavement, and 98 $(2.0 \%)$ participants lost relatives. The individuals who experienced the earthquake with or without bereavement were younger and were more likely to have lived in Tangshan 1 to 2 years after the earthquake than those who had not experienced the earthquake $(12.1 \pm 9.0$, $13.1 \pm 9.1$ and $14.8 \pm 9.2$ years, respectively, for age; $86.7 \%$, $79.4 \%$ and $1 \%$, respectively, for residence). No differences were found in gender, smoking status, drinking status, education, income, hypertension, diabetes or dyslipidaemia. A higher incidence of depression was observed in the bereaved and non-bereaved earthquake survivors $(12.2 \%(12 / 98)$ and $7.2 \%(39 / 543)$, respectively) than in those without earthquake experience $(4.9 \%(215 / 4383))$.

\section{Association between earthquake experience and depression}

ORs and 95\% CIs for the association between earthquake experience and depression are presented in table 2. The risk of depression in the bereaved subgroup was 2.82 times (OR 2.82, 95\% CI 1.24 to 6.39) higher than that in the group with no earthquake experience after adjusting for gender, age at the time of the earthquake, smoking status, drinking status, education, income, residence in Tangshan 1 to 2 years after the earthquake, hypertension, diabetes and dyslipidaemia. However, no statistically significant association was found in the non-bereaved group. 
Table 1 Population characteristics according to earthquake experience

\begin{tabular}{|c|c|c|c|c|c|}
\hline Characteristics & Overall & $\begin{array}{l}\text { No experience } \\
(n=4383)\end{array}$ & $\begin{array}{l}\text { Experience without } \\
\text { bereavement } \\
(n=543)\end{array}$ & $\begin{array}{l}\text { Experience with } \\
\text { bereavement }(n=98)\end{array}$ & $P$ value \\
\hline Men, $\mathrm{n}(\%)$ & $2524(50.2)$ & $2210(50.4)$ & $276(50.8)$ & 38 (38.8) & 0.071 \\
\hline $\begin{array}{l}\text { Age at the time of the } \\
\text { earthquake, mean (SD) }\end{array}$ & $14.6 \pm 9.2$ & $14.8 \pm 9.2$ & $13.1 \pm 9.1$ & $12.1 \pm 9.0$ & $<0.001$ \\
\hline$\leq 6$ & $1063(21.2)$ & $880(20.08)$ & $146(26.89)$ & $37(37.76)$ & $<0.001$ \\
\hline $6-18$ & $2053(40.9)$ & $1796(40.98)$ & $226(41.62)$ & $31(31.63)$ & \\
\hline$\geq 18$ & $1908(38.0)$ & 1707 (38.95) & $171(31.49)$ & $30(30.61)$ & \\
\hline Smoking, n (\%) & $1286(25.6)$ & $1136(25.9)$ & $132(24.3)$ & $18(18.4)$ & 0.182 \\
\hline Drinking, $\mathrm{n}(\%)$ & $1578(31.4)$ & $1364(31.1)$ & $186(34.3)$ & $28(28.6)$ & 0.276 \\
\hline Education, n (\%) & & & & & 0.689 \\
\hline Illiteracy/primary & $318(6.3)$ & $279(6.4)$ & $31(5.7)$ & $8(8.2)$ & \\
\hline Middle school/high school & $2704(53.8)$ & $2370(54.1)$ & $282(51.9)$ & $52(53.1)$ & \\
\hline University or above & $2002(39.9)$ & $1734(39.6)$ & $230(42.4)$ & $38(38.8)$ & \\
\hline Income, n (\%) & & & & & 0.127 \\
\hline$\leq 3000$ & $2415(48.1)$ & $2087(47.6)$ & $270(49.7)$ & $58(59.2)$ & \\
\hline $3001-5000$ & $2278(45.3)$ & $2002(45.7)$ & $243(44.8)$ & $33(33.7)$ & \\
\hline$>5000$ & $331(6.6)$ & $294(6.7)$ & $30(5.5)$ & $7(7.1)$ & \\
\hline $\begin{array}{l}\text { Residence in Tangshan } 1-2 \\
\text { years after the earthquake, } n \\
(\%)\end{array}$ & $561(11.2)$ & $45(1.0)$ & $431(79.4)$ & $85(86.7)$ & $<0.001$ \\
\hline Hypertension, n (\%) & $2158(43.0)$ & $1872(42.7)$ & $237(43.7)$ & $45(45.9)$ & 0.463 \\
\hline Diabetes, n (\%) & $550(11.0)$ & 497 (11.3) & $43(7.9)$ & 10 (10.2) & 0.054 \\
\hline Dyslipidaemia, n (\%) & $3102(61.7)$ & $2696(61.5)$ & 343 (63.2) & 63 (64.3) & 0.659 \\
\hline Depression, n (\%) & 266 (5.3) & $215(4.9)$ & $39(7.2)$ & $12(12.2)$ & 0.001 \\
\hline
\end{tabular}

Subgroup analysis by gender and age as of the earthquake

In the models stratified by gender, the female subjects in both the bereaved (OR 3.51, 95\% CI 1.21 to 10.16) and non-bereaved (OR 3.07, 95\% CI 1.44 to 6.56 ) subgroups had an increased risk of depression. In contrast, no significant association was found between earthquake experience and the risk of depression among male subjects in either the bereaved (OR 2.09, 95\% CI 0.58 to 7.61 ) or the non-bereaved (OR $0.84,95 \% \mathrm{CI} 0.32$ to 2.20 ) subgroup.
In the models stratified by age at the time of the earthquake, we found a statistically significant association in individuals over 18 years old whether they had lost relatives in the earthquake (OR 13.16, 95\% CI 3.08 to 56.3) or not (OR 3.39, 95\% CI 1.31 to 8.87 ). No statistically significant association was found in survivors under 6 years old whether they had been bereaved (OR 1.65, 95\% CI 0.42 to 6.49 ) or not (OR 1.09, $95 \%$ CI 0.36 to 3.27 ), and there was also no significant association in survivors aged

Table 2 ORs for the association between earthquake experience and depression

\begin{tabular}{|c|c|c|c|}
\hline & $\begin{array}{l}\text { No earthquake experience } \\
(n=4383,87.2 \%)\end{array}$ & $\begin{array}{l}\text { Experience without bereavement } \\
(n=543,10.8 \%)\end{array}$ & $\begin{array}{l}\text { Experience with bereavement } \\
(n=98,2.0 \%)\end{array}$ \\
\hline Model 1 & 1 & $1.42(0.99-2.20)$ & $2.46(1.32-4.59)$ \\
\hline Model 3 & 1 & $1.61(0.88-2.95)$ & $2.88(1.26-6.57)$ \\
\hline Model 4 & 1 & 1.69 (0.93-3.08) & $2.82(1.24-6.39)$ \\
\hline
\end{tabular}

Model 1 refers to the unadjusted model.

Model 2 refers to the model adjusted for gender and age at the time of the earthquake.

Model 3 refers to the model adjusted for gender, age at the time of the earthquake, smoking status, drinking status, education, income and residence in Tangshan 1 to 2 years after the earthquake.

Model 4 refers to the model adjusted for gender, age at the time of the earthquake, smoking status, drinking status, education, income, residence in Tangshan 1 to 2 years after the earthquake, hypertension, diabetes and dyslipidaemia. 
Non-bereaved VS.No experience Odds Ratio $(95 \%$ CI)
Bereaved VS.No experience Odds Ratio (95\% CI)
Interaction

$P$-value

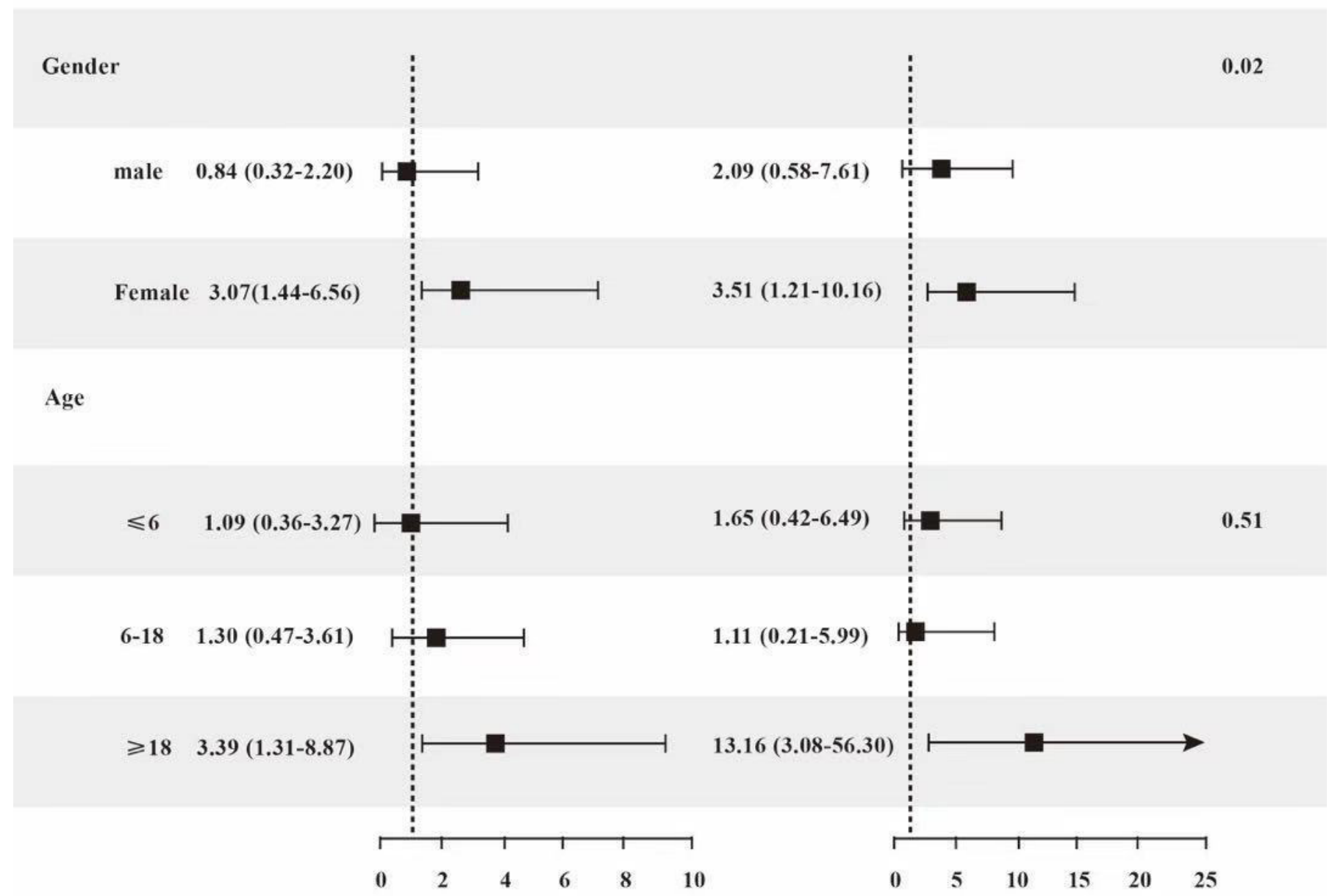

Figure 1 OR of depression given earthquake experience, stratified by gender and age at the time of the earthquake. Groups stratified by gender, adjusted for age at the time of the earthquake, smoking status, drinking status, education, income, residence in Tangshan 1 to 2 years after the earthquake, hypertension, diabetes and dyslipidaemia. Groups stratified by age at the time of the earthquake, adjusted for gender, smoking status, drinking status, education, income, residence in Tangshan 1 to 2 years after the earthquake, hypertension, diabetes and dyslipidaemia.

between 6 and 18 years whether they had lost relatives (OR $1.11,95 \%$ CI 0.21 to 5.99 ) or not (OR $1.30,95 \%$ CI 0.47 to 3.61 ).In addition, we found a statistically significant interaction between gender and depression ( $\mathrm{p}$ for interaction $=0.02$ ) but no significant interaction between age at the time of the earthquake and depression ( $p$ for interaction=0.51) (figure 1).

\section{DISCUSSION}

In this community-based study, we observed that, even after 37 years, earthquake survivors had a higher risk of depression than those who had not experienced the earthquake. In addition, long-term effects of the earthquake on depression were found among bereaved survivors, women and individuals over 18 years old. This study is the first to investigate the association between earthquake experience and depression 37 years after an earthquake.
Evidence shows that traumatic experiences in childhood and adolescence may have a determining effect on brain structural development, sympathetic nervous system responsivity and the hypothalamic-pituitaryadrenal axis, especially in younger children (preschool) and school-age children (late childhood and early adolescence), resulting in a large stress response and some psychological problems. ${ }^{18}$ Therefore, we classified the participants into age categories of 0 to 6,6 to 18 and older than 18 years to investigate the long-term impact of disaster on mental health during different stages of life. However, statistically significant associations were found only in individuals over 18 years of age. One explanation is that different ages have different needs for social networks. Social networking is associated with the onset of depression. ${ }^{34}$ Children's and adolescents' social needs are met by parental care and family. ${ }^{35}$ Adults, in contrast, need support from social interaction in the 
neighbourhood, the communities and the work place in addition to family support. ${ }^{36}$ The advent of the earthquake destroyed the previously stable social networks and economic foundation of the community. Social-network destruction may lead to some mental health disorders. Additionally, survivors under 18 years old recover from disaster more easily than older survivors do. Insensitivity to the nature and meaning of disaster trauma ${ }^{37}$ and access to mental health intervention in the early post-disaster stages $^{38}$ may contribute to recovery from psychological problems among child and adolescent survivors.

With regard to gender, we found a significant association between earthquake experience and depression in women but not in men. Similar results have been found in several previous studies of disaster, indicating that women may be at a higher risk of depression than men when they experienced disasters including large earthquake. ${ }^{13} 19$ Differences in physiology, personality, social role and rumination between women and men might result in this gender difference in the association between depression and disaster. ${ }^{39-43}$ The exact causal factors leading to gender differences in long-term effects of earthquakes remains a big challenge for future researches.

Consistent with our findings, a longitudinal study on the Alexander Kielland oil platform collapse shows that survivors have a higher risk of depression than non-exposed individuals 27 years after the disaster. ${ }^{15}$ Similar results are observed in another longitudinal study with 10 years of follow-up, which indicates that survivors of the Piper Alpha oil platform disaster show a long-lasting increase in mental health problems compared with non-exposed individuals. ${ }^{16}$ In contrast, two studies indicate that disaster has little long-term effect on depression. ${ }^{1314}$ The inconsistency of the results may be explained by the severity of the disaster. The Tangshan earthquake caused more damage than the Buffalo Creek dam collapse or the Australian bushfire disaster. The earthquake reduced Tangshan to ruins in a few minutes, with approximately $85 \%$ of the buildings collapsed and at least 400000 casualties. ${ }^{2044}$ The earthquake afflicted the survivors with not only the loss of their homes but also, more importantly, the tension and fear brought by the disaster itself, the loss of loved ones, the complete destruction of social networks and a sense of despair. ${ }^{45}$ During the long-term urban reconstruction process, all these effects of the disaster might lead to long-term adverse psychological effects on the survivors. In addition, the Tangshan earthquake broke out at the end of the decade of the Cultural Revolution. The consequences of the Cultural Revolution, which include a fragile economic foundation, low economic compensation, lack of societal acknowledgement and destruction of the healthcare service network, may have delayed recovery.

The long-term effect of disaster on depression seems to depend on traumatic experience. In our study, a statistically significant association between earthquake experience and depression was observed in bereaved survivors but not in non-bereaved survivors 37 years after the earthquake. This finding was consistent with a longitudinal study carried out in Italy showing that exposure to loss and damage during an earthquake confers an additional risk of negative psychological consequences above and beyond living in the earthquake zone. ${ }^{10}$ Similarly, a longitudinal study 14 years after MS Estonia Disaster indicated that non-bereaved survivors recovered from their post-traumatic stress reactions, while little change was found over that period in the reaction of the bereaved. ${ }^{12}$ Traumatic bereavement may be associated with increased severity of long-term post-traumatic stress reactions after disasters, ${ }^{47}$ which is considered to be involved in the onset of depression. ${ }^{4}$

Several plausible explanations may link earthquake exposure to the prevalence of depressive symptoms. Earthquakes can cause tremendous, immediate damage to the environment and even lead to adverse life events such as the death of a family member and related events, thus exerting negative effects on individuals' emotions and resulting in post-traumatic stress disorder (PTSD) after the disaster. ${ }^{412}$ PTSD, as a frequent comorbidity of depression, ${ }^{48}{ }^{49}$ may persist for decades following disaster. ${ }^{50-52}$ These findings suggest that traumatic bereavement might be a common mediating mechanism of both depression and PTSD. The pain of loss in survivors may have neurobiological effects on several brain areas (the frontolimbic and striatal areas). ${ }^{4753}$ These areas and the functional connectivity within the fronto-striato-thalamic and default-mode networks have been found to be correlated with the progression of mental health problems and may play important roles in adaptation to trauma. ${ }^{454}$ The trauma caused by disasters has a variety of mechanisms. Whether PTSD symptoms further transform into depression or other mental illnesses in the long-term will require further exploration.

Gender, age at the time of the earthquake, education, income, smoking, drinking, living in the affected area after a disaster, hypertension, diabetes and dyslipidaemia were controlled in the multiple variable analysis. To avoid over fitting, we used four models to adjust confounding variables step by step. The resulting ORs reflected minor changes in the four models, suggesting that earthquake experience may be an independent risk factor for the occurrence of depression.

Our study has a few limitations. First, substantial time has passed since the earthquake occurred, and we were unable to control for every event or factor. For example, we did not consider other traumatic events, such as traffic accidents, adverse childhood experiences, other bereavement or current psychological stressors, which could have confounded the observed associations. Additionally, the sample was not representative of all survivors of the Tangshan earthquake. We did not include survivors who had died in the past 37 years. Premature death may be related to depression and disease. Meanwhile, in our sample, nearly $20 \%$ of the survivors did not live in the earthquake zone 1 to 2 years after the earthquake. 
These people left the painful environment and may have worked or attended school elsewhere for several years, which may have largely relieved psychological stress and alleviated the symptoms of depression. Therefore, the potential impacts of the earthquake on depression may have been underestimated. Third, whether the subjects were taking antidepressants was unknown. Fourth, the cross-sectional design of this study precludes causal inferences. Finally, depression was assessed only once during the study; therefore, we could not exclude the possibility of reverse causality.

The results of our study are very relevant to future research on depression among disaster survivors. For instance, survivors of earthquakes in Japan, Haiti and China were all affected by high rates of depression in the short term. ${ }^{55-58}$ Although the timing and severity of the disasters, the ethnicity of the affected population and the living environment of the survivors are different, the stressors caused by disasters are similar. Strengthening community social cohesion can facilitate recovery from disaster trauma. ${ }^{5960}$ Clinicians and policymakers in public health should direct additional early social support towards high-risk survivors of disasters, a measure that may reduce the incidence of mental health problems, including depression, in disaster zones ${ }^{61}$ even long after the disaster has passed.

\section{CONCLUSIONS}

Thirty-sevenyears after the disaster, earthquake experience was associated with depression among bereaved survivors, women and individuals over 18 years old at the time of the earthquake. Our study provides evidence supporting the hypothesis that the effect of an earthquake on depression persists for at least 37 years.

\section{Author affiliations \\ ${ }^{1}$ Institute of Medical Information, Chinese Academy of Medical Sciences and Peking Union Medical College, Beijing, China \\ ${ }^{2}$ Global Brain Health Institute, Department of Psychiatry, University of California, San Francisco, California, USA \\ ${ }^{3}$ Department of Physiology and Pathophysiology, School of Basic Medical Sciences Key Laboratory of Molecular Cardiovascular Science of the Ministry of Education Center for Non-coding RNA Medicine, Peking University Health Science Center, Beijing, China \\ ${ }^{4}$ Hypertension Center, Fuwai Hospital, Chinese Academy of Medical Sciences and Peking Union Medical College, State Key Laboratory of Cardiovascular Disease, Beijing, China \\ ${ }^{5}$ Sanbo Brain Institute, Sanbo Brain Hospital, Capital Medical University, Beijing, China}

Acknowledgements We thank all the participants, patient advisers and members of the survey team in the Jidong community. We also appreciate the help and support we received from the staff of Ruike Donghua Co., Ltd. During the review period, Yong Zhou transferred to a different employer; his address was changed accordingly. We guarantee that all authors have approved the changes in the author list.

Contributors All authors were involved from the beginning in all phases of the study. XG, YZ and HPH designed the study. XG and YL analysed the data and prepared the manuscript. JCY, QHC and BG critiqued the manuscript for important intellectual content. XG and YCG conducted the statistical analysis. All authors have read and approved the final version of this manuscript.
Funding This work was supported by the National Natural Science Foundation (No. 81473057, No.81202279), the National Social Science Fund (No.17BGL184) and the Non-profit Central Research Institute Fund of Chinese Academy of Medical Sciences (No.2017PT63009).

Competing interests None declared.

Patient consent for publication Not required.

Ethics approval The research was approved by the Ethics Committee of Jidong Oilfield Staff Hospital.

Provenance and peer review Not commissioned; externally peer reviewed.

Data availability statement Data are available upon reasonable request.

Open access This is an open access article distributed in accordance with the Creative Commons Attribution Non Commercial (CC BY-NC 4.0) license, which permits others to distribute, remix, adapt, build upon this work non-commercially, and license their derivative works on different terms, provided the original work is properly cited, appropriate credit is given, any changes made indicated, and the use is non-commercial. See: http://creativecommons.org/licenses/by-nc/4.0/.

\section{REFERENCES}

1. Who W, Mathers C, Fat DM, et al. The global burden of disease: 2004 update. Irish Medical Journal 2008;106:4.

2. Krishnan V, Nestler EJ. The molecular neurobiology of depression. Nature 2008;455:894-902.

3. Guo J, He H, Fu M, et al. Suicidality associated with PTSD, depression, and disaster recovery status among adult survivors 8 years after the 2008 Wenchuan earthquake in China. Psychiatry Res 2017;253:383-90.

4. Yang L, Zhao Y, Wang Y, et al. The effects of psychological stress on depression. Curr Neuropharmacol 2015;13:494-504.

5. Madden JS. Alcohol and depression. Br J Hosp Med 1993;50:261-4.

6. Gu L, Xie J, Long J, et al. Epidemiology of major depressive disorder in mainland China: a systematic review. PLoS One 2013;8:e65356.

7. Kessler RC, Berglund P, Demler O, et al. The epidemiology of major depressive disorder: results from the National comorbidity survey replication (NCS-R). Jama 2003;289:3095-105.

8. van Griensven Fet al. Mental health problems among adults in tsunami-affected areas in southern Thailand. JAMA 2006;296:537-48.

9. Fergusson DM, Horwood LJ, Boden JM, et al. Impact of a major disaster on the mental health of a well-studied cohort. JAMA Psychiatry 2014;71:1025-31.

10. Bland $\mathrm{SH}, \mathrm{O}^{\prime}$ Leary ES, Farinaro $\mathrm{E}$, et al. Long-Term psychological effects of natural disasters. Psychosom Med 1996;58:18-24.

11. Bryant RA, Creamer M, O'Donnell M, et al. Acute and chronic posttraumatic stress symptoms in the emergence of posttraumatic stress disorder. JAMA Psychiatry 2017;74:135-42.

12. Arnberg FK, Eriksson N-G, Hultman CM, et al. Traumatic bereavement, acute dissociation, and posttraumatic stress: 14 years after the MS Estonia disaster. J Trauma Stress 2011;24:183-90.

13. Green BL, Grace MC, Vary MG, et al. Children of disaster in the second decade: a 17-year follow-up of buffalo creek survivors. J Am Acad Child Adolesc Psychiatry 1994;33:71-9.

14. McFarlane AC, Van Hooff M. Impact of childhood exposure to a natural disaster on adult mental health: 20-year longitudinal follow-up study. British Journal of Psychiatry 2009;195:142-8.

15. Boe HJ, Holgersen KH, Holen A. Mental health outcomes and predictors of chronic disorders after the North Sea oil rig disaster: 27-year longitudinal follow-up study. J Nerv Ment Dis 2011;199:49-54.

16. Hull AM, Alexander DA, Klein S. Survivors of the Piper alpha oil platform disaster: long-term follow-up study. British Journal of Psychiatry 2002;181:433-8.

17. Norris FPJ, Kaniasty K. Individual and community responses to trauma and disaster: individual and community reactions to the Kentucky floods: findings from a longitudinal study of older adults. Cambridge University Press, 1994.

18. Shaw JA. Children, adolescents and trauma. Psychiatr $Q$ 2000;71:227-43.

19. Guo J, He H, Qu Z, et al. Post-Traumatic stress disorder and depression among adult survivors 8 years after the 2008 Wenchuan earthquake in China. J Affect Disord 2017;210:27-34.

20. Sheng ZY. Medical support in the Tangshan earthquake: a review of the management of mass casualties and certain major injuries. $J$ Trauma 1987;27:1130-5. 
21. An C, Zhang Y, Yu L, et al. Long-Term impact of earthquake stress on fasting glucose control and diabetes prevalence among Chinese adults of Tangshan. Int J Clin Exp Med 2014;7:4441-7.

22. Ji C, Li Y, Cui L, et al. Prenatal earthquake exposure and midlife uric acid levels among Chinese adults. Arthritis Care Res 2017;69:703-8.

23. Li N, Wang Y, Yu L, et al. Long-Term effects of earthquake experience of young persons on cardiovascular disease risk factors. Archives of Medical Science 2017;1:75-81.

24. Guo Y-C, Zhou Y, Gao X, et al. Association between nonalcoholic fatty liver disease and carotid artery disease in a community-based Chinese population. Chin Med J 2018;131:2269-76.

25. Song Q, Liu X, Wang A, et al. Associations between non-traditional lipid measures and risk for type 2 diabetes mellitus in a Chinese community population: a cross-sectional study. Lipids Health Dis 2016;15:70

26. Hao Z, Zhang Y, Li Y, et al. The association between ideal cardiovascular health metrics and extracranial carotid artery stenosis in a northern Chinese population: a cross-sectional study. Sci Rep 2016;6:31720.

27. Han X, Yang Y, Chen Y, et al. Association between insomnia and atrial fibrillation in a Chinese population: a cross-sectional study. Clin Cardiol 2017;40:765-9.

28. Wang Y, Ge S, Yan Y, et al. China suboptimal health cohort study: rationale, design and baseline characteristics. $J$ Transl Med 2016;14:291.

29. Radloff LS. The CES-D scale. Appl Psychol Meas 1977;1:385-401.

30. Chien CP, Cheng TA. Depression in Taiwan: epidemiological survey utilizing CES-D. Seishin Shinkeigaku Zasshi 1985;87:335-8.

31. Zhang Y, Ting RZW, Lam MHB, et al. Measuring depression with CES-D in Chinese patients with type 2 diabetes: the validity and its comparison to PHQ-9. BMC Psychiatry 2015;15:198.

32. Zhang J, Sun W, Kong Y, et al. Reliability and validity of the center for epidemiological studies depression scale in 2 special adult samples from rural China. Compr Psychiatry 2012:53:1243-51.

33. Wang F, Liu J, Liu L, et al. The status and correlates of depression and anxiety among breast-cancer survivors in eastern China: a population-based, cross-sectional case-control study. BMC Public Health 2014;14:326.

34. Rosenquist JN, Fowler JH, Christakis NA. Social network determinants of depression. Mol Psychiatry 2011;16:273-81.

35. McFarlane AC. Posttraumatic phenomena in a longitudinal study of children following a natural disaster. Journal of the American Academy of Child \& Adolescent Psychiatry 1987;26:764-9.

36. Bland SH, O'Leary ES, Farinaro E, et al. Social network disturbances and psychological distress following earthquake evacuation. $J$ Nervous Mental Disease 1997;185:188-95.

37. Green BL, Korol M, Grace MC, et al. Children and disaster: age, gender, and parental effects on PTSD symptoms. J Am Acad Child Adolesc Psychiatry 1991;30:945-51.

38. Wang C-W, Chan CLW, Ho RTH. Prevalence and trajectory of psychopathology among child and adolescent survivors of disasters: a systematic review of epidemiological studies across 1987-2011. Soc Psychiatry Psychiatr Epidemiol 2013;48:1697-720.

39. Feingold A. Gender differences in personality: a meta-analysis. Psychol Bull 1994:116:429-56.

40. Christov-Moore L, Simpson EA, Coudé G, et al. Empathy: gender effects in brain and behavior. Neurosci Biobehav Rev 2014;46 Pt 4:604-27.

41. Ranasinghe PD, Levy BR. Prevalence of and sex disparities in posttraumatic stress disorder in an internally displaced Sri Lankan population 6 months after the 2004 tsunami. Disaster Med Public Health Prep 2007;1:34-41. Discussion 41-3.
42. Aksaray G, Kortan G, Erkaya H, et al. Gender differences in psychological effect of the August 1999 earthquake in turkey. Nord $\mathrm{J}$ Psychiatry 2006;60:387-91.

43. Nolen-Hoeksema S, Harrell ZA, Rumination HZA. Rumination, depression, and alcohol use: tests of gender differences. J Cogn Psychother 2002;16:391-403.

44. Liu H, Housner GW, Xie L, et al. The great Tangshan earthquake of 1976. California Institute of Technology 2002.

45. Armenian HK, Morikawa M, Melkonian AK, et al. Loss as a determinant of PTSD in a cohort of adult survivors of the 1988 earthquake in Armenia: implications for policy. Acta Psychiatr Scand 2000;102:58-64.

46. Carr VJ, Lewin TJ, Webster RA, et al. Psychosocial sequelae of the 1989 Newcastle earthquake: II. exposure and morbidity profiles during the first 2 years post-disaster. Psychol Med 1997;27:167-78.

47. Green BL, Lindy JD, Grace MC, et al. Chronic posttraumatic stress disorder and diagnostic comorbidity in a disaster sample. J Nerv Ment Dis 1992:180:760-6.

48. Breslau N, Davis GC, Peterson EL, et al. A second look at comorbidity in victims of trauma: the posttraumatic stress disordermajor depression connection. Biol Psychiatry 2000;48:902-9.

49. Bașoğlu M, Kiliç $C$, Salcioğlu E, et al. Prevalence of posttraumatic stress disorder and comorbid depression in earthquake survivors in turkey: an epidemiological study. J Trauma Stress 2004;17:133-41.

50. Marshall GNet al. Mental health of Cambodian refugees 2 decades after resettlement in the United States. JAMA 2005;294:571-9.

51. Goenjian AK, Khachadourian V, Armenian $\mathrm{H}$, et al. Posttraumatic stress disorder 23 years after the 1988 Spitak earthquake in Armenia. J Trauma Stress 2018;31:47-56.

52. Morgan L, Scourfield J, Williams D, et al. The Aberfan disaster: 33-year follow-up of survivors. British Journal of Psychiatry 2003;182:532-6.

53. McFarlane AC. The prevalence and longitudinal course of PTSD. Implications for the neurobiological models of PTSD. Annals of the New York Academy of Sciences 1997;821:10-23.

54. Long J, Huang X, Liao Y, et al. Prediction of post-earthquake depressive and anxiety symptoms: a longitudinal resting-state fMR study. Sci Rep 2015;4:6423.

55. Guo J, Wu P, Tian D, et al. Post-Traumatic stress disorder among adult survivors of the Wenchuan earthquake in China: a repeated cross-sectional study. J Anxiety Disord 2014;28:75-82.

56. Ye Y, Fan F, Li L, et al. Trajectory and predictors of depressive symptoms among adolescent survivors following the Wenchuan earthquake in China: a cohort study. Soc Psychiatry Psychiatr Epidemiol 2014;49:943-52.

57. Matsubara $\mathrm{C}$, Murakami H, Imai K, et al. Prevalence and risk factors for depressive reaction among resident survivors after the tsunami following the great East Japan earthquake, March 11, 2011. PLoS One 2014;9:e109240.

58. Cerdá M, Paczkowski M, Galea S, et al. Psychopathology in the aftermath of the Haiti earthquake: a population-based study of posttraumatic stress disorder and major depression. Depress Anxiety 2013;30:413-24.

59. Hikichi H, Aida J, Tsuboya T, et al. Can community social cohesion prevent posttraumatic stress disorder in the aftermath of a disaster? a natural experiment from the 2011 Tohoku earthquake and tsunami. Am J Epidemiol 2016;183:902-10.

60. North CS, Pfefferbaum B. Mental health response to community disasters: a systematic review. Jama 2013;310.

61. Salcioğlu E, Bașoğlu M. Psychological effects of earthquakes in children: prospects for brief behavioral treatment. World $\mathrm{J}$ Pediatr 2008;4:165-72. 